\section{Schedule induction: A reply to Timberlake and to Wetherington and Brownstein}

\author{
T. J. ROPER \\ University of Sussex, Brighton, England
}

Scholarly wrangles about terminology and methodology seem to the layman to typify academic smallmindedness, and, in any case, for one member of the scientific community to lay down laws about the conduct of experiments and the use of language smacks of impertinence. But, as Timberlake (1982) reminds us, the methods that we use to investigate a phenomenon and the language that we use to describe the results are inextricably bound up with our theoretical perceptions about the causation of that phenomenon. Hence, a good definition can act as a springboard to understanding, a bad one as a straightjacket. My "working definition" of schedule induction (Roper, 1981) was intended to focus attention on what I consider to be the single most important feature of schedule-induced behavior, namely, its "excessiveness'-a feature that seemed in danger of being forgotten in the tangle of research. I refer to the definition as a working one because the time to settle on a final definition will be when we have a full understanding of the phenomenon. Above all, however, I was trying to provoke fresh thought about the phenomenon of induction, and I am grateful to Timberlake and to Wetherington and Brownstein (1982) for turning the monologue into a discussion.

Admittedly, there are problems with the straightforward rate measure of induced behavior that I advocated, but I suspect that there are also problems with the idea of measuring opportunity for a behavior to occur. Because drinking cannot occur at the same time as eating, it is argued that a measure of the time available for drinking should exclude time spent eating. But what about all the other important activities in which the animal engages, such as grooming and wandering around the experimental chamber? If we subtract these from the total session duration we end up with a tautology: opportunity to drink is equal to time spent actually drinking. The notion of opportunity makes assumptions about the priority given to different behaviors, and these assumptions may not always be easy to justify independently.

As noted above, my definition of schedule induction focused on a single attribute of behavior that I happen to consider important. Timberlake asks why changes in temporal pattern or sequence should not be given equal

The author's mailing address is: School of Biology, University of Sussex, Brighton BN1 9QG, England. weighting in a definition of induction. The reason is that, while some adjunctive behaviors (e.g., drinking) undergo both an increase in overall rate and a change in temporal patterning, others (e.g., running, grooming) undergo only a change in temporal patterning. Now, it may be the case that the change in temporal patterning is more fundamental in the sense that if we understand that, then we shall also understand why an increase in overall rate is sometimes generated. Being a cautious person, however, I prefer for the time being to keep these two aspects of interreinforcement behavior in separate mental compartments, in recognition of the fact that they are not inevitably correlated. I am not denying the importance of temporal patterning as a subject of inquiry: far from it, I am just saying that it may not prove to be the same thing, from a causal point of view, as the increase in overall frequency that I have termed schedule induction. I share Wetherington and Brownstein's hope that we shall eventually have a complete theory of adjunctive behavior that encompasses all aspects of the phenomenon.

The precise labels that are attached to different categories of behavior are less important than our keeping the categories distinct in our minds. Wetherington and Brownstein criticize my use of "adjunctive" as a generic term for both induced and noninduced behavior, on the grounds that "adjunctive" has often been used as a synonym for "schedule-induced." This is putting the cart before the horse. When I suggest that "adjunctive" be treated as a generic term I am not inventing a new usage: this is precisely how the term is commonly used at present. The term whose use I am trying to change is "schedule-induced," which has, to my mind regrettably, come to be treated as a synonym for "adjunctive"! In an ideal world it would probably profit us to abolish the entire accumulated terminology and start again, but "schedule-induced" and "adjunctive" are too well established to submit to such treatment. I persist in believing that "schedule-modulated" could most usefully be applied to noninduced behavior that is subject to temporal control-a category for which we lack a label.

\section{REFERENCES}

ROPER, T. J. What is meant by the term "schedule-induced," and how general is schedule induction? Animal Learning \& Behavior, 1981, 4, 433-440.

Tmmberlake, W. Controls and schedule-induced behavior. AniLearning \& Behavior, 1982, 10, 535-536.

Wetherinaton, C. L., \& Brownstein, A. J. Comment on Roper's discussion of the language and generality of scheduleinduced behavior. Animal Learning \& Behavior, 1982, 10, 537-539.

(Manuscript received August 31, 1982;

accepted for publication August 31, 1982.) 